\title{
Study on thermoelectric performance by Na doping in nanostructured $\mathrm{Mg}_{1-x} \mathrm{Na}_{x} \mathrm{Ag}_{0.97} \mathrm{Sb}_{0.99}$
}

\author{
Jing Shuai ${ }^{\mathrm{a}}$, Hee Seok Kimª, Yucheng Lan ${ }^{\mathrm{a}}$, Shuo Chen ${ }^{\mathrm{a}}$, Yuan Liu', Huaizhou Zhao ${ }^{\mathrm{a}}$, \\ Jiehe Sui ${ }^{\mathrm{a}, \mathrm{b}^{*}}$, and Zhifeng Ren ${ }^{\mathrm{a}^{*}}$ \\ ${ }^{a}$ Department of Physics and TcSUH, University of Houston, Houston, TX 77204, USA \\ ${ }^{b}$ National Key Laboratory for Precision Hot Processing of Metals and School of \\ Materials Science and Engineering, Harbin Institute of Technology, Harbin 150001, \\ China
}

\begin{abstract}
$\mathrm{MgAg}_{0.97} \mathrm{Sb}_{0.99}$ was found to be potentially a new class of thermoelectric materials with $Z T$ values above 1 in the temperature from 100 to $300{ }^{\circ} \mathrm{C}$. In this report, we systematically studied the effect of $\mathrm{Na}$ doping in $\mathrm{Mg}, \mathrm{Mg}_{1-x} \mathrm{Na}_{x} \mathrm{Ag}_{0.97} \mathrm{Sb}_{0.99}$, on the thermoelectric properties and found $\mathrm{Na}$ was effective to increase the carrier concentration and power factor, especially below $180{ }^{\circ} \mathrm{C}$, which led to higher $Z T$ values, a better selfcompatibility factor, and ultimately a higher output power at the optimal $\mathrm{Na}$ concentration of $\mathrm{x}=0.005-0.0075$.
\end{abstract}

KEYWORDS: MgAgSb alloys; nanostructure; thermoelectric; self-compatibility factor; output power; efficiency

*Corresponding authors. Tel.: +1 713743 8217; fax: +1 7137438201.

E-mail address: zren@uh.edu (Z. Ren), suijiehe@hit.edu.cn (J. Sui) 


\section{Introduction}

Recent years have witnessed extensive studies on thermoelectric (TE) materials, which may play an important role in future energy conversion, production, management, and supply [1-5]. The efficiency of a TE material in a power generator or heat pump depends on the dimensionless thermoelectric figure of merit, $Z T$, defined as $Z T=\left(S^{2} \sigma / \kappa\right) T$, where $S, \sigma, \kappa$, and $T$ are the Seebeck coefficient, electrical conductivity, thermal conductivity, and absolute temperature, respectively [6, 7]. The numerator $S^{2} \sigma$ is called power factor PF. Even though PF could be enhanced by engineering the electronic structure, and $\kappa$ could be reduced by increasing the phonon scattering, it is very difficult to independently optimize them simultaneously since they are interrelated. The concept of "phonon-glass electron-crystal, PGEC” has been considered to be an effective way to decouple these interrelated quantities, but the experimental success is limited in only a few materials so far [8-10]. Recently, nanostructure approach was found to be the major technique for $Z T$ enhancement by reducing the thermal conductivity and in some cases simultaneously improving the PF [11-14].

Several classes of materials currently under investigation including $\mathrm{PbTe}, \mathrm{PbSe}$, and their doped compounds [15-18], skutterudites [19-21], metal oxides [22, 23], and half Heuslers [24-29] are suitable for the intermediate temperature range (300-500 ${ }^{\circ} \mathrm{C}$ ) and high temperature range $\left(500-1000^{\circ} \mathrm{C}\right)$. However, for applications below $300{ }^{\circ} \mathrm{C}$, there is no other material than $\mathrm{Bi}_{2} \mathrm{Te}_{3}$ with $Z T$ close to $1.4[6,30,31]$ till recently when MgAgSb and its modified composition $\mathrm{MgAg}_{0.97} \mathrm{Sb}_{0.99}[32,33]$ were reported to have similar $Z T \mathrm{~s}$. $\mathrm{MgAg}_{0.97} \mathrm{Sb}_{0.99}$ exhibited $Z T$ of $\sim 0.7$ at room temperature and of 1.2 at $200{ }^{\circ} \mathrm{C}$. A small amount of Ni has been used to alloy the Ag site and has resulted in enhancement of $Z T$ to $\sim 1$ at $50{ }^{\circ} \mathrm{C}$ and $\sim 1.4$ at $180{ }^{\circ} \mathrm{C}$. Herein, we report our effort on $\mathrm{Na}$ doping on $\mathrm{Mg}$ to make $\mathrm{Mg}_{1-x} \mathrm{Na}_{x} \mathrm{Ag}_{0.97} \mathrm{Sb}_{0.99}$ with $x=0.005,0.0075$, and 0.01 . Na has been considered as an ideal hole dopant with little effect on the other physical properties in many materials [34, 35]. It was found that the enhancement of thermoelectric properties mainly comes from the increased PF, leading to higher ZTs, better self-compatibility factors, and output power.

\section{Experimental Details}

Synthesis process. Based on the undoped phase-pure composition $\mathrm{MgAg} \mathrm{Ag}_{0.97} \mathrm{Sb}_{0.99}$, we studied substitution of Mg by $\mathrm{Na}$ by the two-step process [33]. First, elemental 
magnesium metal pieces (Mg, Sigma Aldrich, 99.9\% metal basis), silver metal pieces (Ag, Sigma Aldrich, 99.9\% metal basis), and sodium (Na, Sigma Aldrich, 99.9\% metal basis) were weighed according to the stoichiometry of $\mathrm{Mg}_{1-x} \mathrm{Na}_{x} \mathrm{Ag}_{0.97} \mathrm{Sb}_{0.99}$ with $x=0$, $0.005,0.0075$, and 0.01 and loaded in a stainless steel jar with stainless steel balls for mechanical alloying by a high energy ball mill (SPEX 8000D) for $10 \mathrm{~h}$. After this step, we added antimony chunks (Sb, Sigma Aldrich, 99.8\% metal basis) into the jar to further milling for $8 \mathrm{~h}$. The final nanopowders were then loaded into a graphite die with an inner diameter of $12.7 \mathrm{~mm}$, and consolidated by direct current (DC) hot pressing at $\sim 300{ }^{\circ} \mathrm{C}$ for $5 \mathrm{~min}$.

Characterizations. X-ray diffraction spectra were collected on a PANalytical multipurpose diffractometer with an X'celerator detector (PANalytical X'Pert Pro). The microstructures, examined on a freshly broken surface, were investigated by a scanning electron microscope (SEM, JEOL 6330F). Transmission electron microscope (TEM, JEOL 2010F) was used to explore the details of grain size. The electrical resistivity ( $\rho$ ) and Seebeck coefficient $(S)$ were measured using a four-point direct-current switching method and the static temperature difference method, respectively, both of which were conducted on a commercial system (ULVAC ZEM-3). The thermal conductivity was measured by measuring the thermal diffusivity $(D)$ on a Nano flash apparatus (LFA 447, NETZSCH), specific heat $\left(C_{P}\right)$ on a DSC (404 C, NETZSCH), and volumetric density $(\rho)$ by Archimedes method. The Hall measurement at room temperature was measured using the Physical Properties Measurement System (PPMS D060, Quantum Design).

\section{Results and Discussion}

Figure 1 shows the XRD patterns of all samples. By comparing with the undoped pure phase $\mathrm{MgAg}_{0.97} \mathrm{Sb}_{0.99}$, no detectable impurity phases were found in $\mathrm{Mg}_{1-x} \mathrm{Na}_{x} \mathrm{Ag}_{0.97} \mathrm{Sb}_{0.99}$ $(x=0.005,0.0075$, and 0.01).

To study the influence of $\mathrm{Na}$ doping on the thermoelectric properties of the materials, samples with compositions $\mathrm{Mg}_{1-x} \mathrm{Na}_{x} \mathrm{Ag}_{0.97} \mathrm{Sb}_{0.99}(x=0,0.005,0.0075$, and 0.01) were prepared. As shown in Figure 2(a), the electrical resistivity decreases with increasing Na content till $x=0.0075$, and the electrical resistivity of all the samples increases with temperature first to the maximum around $75-100{ }^{\circ} \mathrm{C}$ and then decrease. When the temperature is above $100{ }^{\circ} \mathrm{C}$, the electrical resistivity decreases, which is consistent with the turning point in the Seebeck coefficient due to bipolar effect in Figure 
2(b). Higher Na content leads to lower electrical resistivity due to the enhanced carrier concentration shown in Table 1. We compared the undoped sample with Na-doped samples of $x=0.005,0.0075$, and 0.01 , and found carrier concentration increases by $32.5 \%, 44.6 \%$ and $43.2 \%$, respectively. The carrier concentration $\left(n_{H}\right)$ and Hall mobility $\left(u_{H}\right)$, which is also shown in Table 1 , affect the electrical resistivity $(\rho)$ by the relationship $1 / \rho=n_{н} е u_{H}$. Figure 2(b) shows the temperature dependent Seebeck coefficient of all the Na doped samples. The Seebeck coefficient decreases with increasing $\mathrm{Na}$ content till $x=0.0075$, and increases with temperature from room temperature to $75-100{ }^{\circ} \mathrm{C}$ before decreases up to $275{ }^{\circ} \mathrm{C}$. Combing the electrical resistivity and Seebeck coefficient, the power factors of all Na doped samples are obtained as shown in Figure 2(c). The increase in power factor with temperature, especially below $100{ }^{\circ} \mathrm{C}$, is pronounced as $\mathrm{Na}$ content increases. The highest power factor among all the samples was found for $x=0.0075$. Na doping effectively optimizes carrier concentration and mobility, leading to lower electrical resistivity, yielding improvement of power factor over the whole temperature range.

Figure 3 shows the thermal transport properties of $\mathrm{Mg}_{1-x} \mathrm{Na}_{x} \mathrm{Ag}_{0.97} \mathrm{Sb}_{0.99}$ with $x=0$, 0.005, 0.0075, and 0.01. Specific heat $\left(C_{p}\right)$ of $\mathrm{MgAg}_{0.97} \mathrm{Sb}_{0.99}$, shown in Figure 3(a), is used for all compositions since replacing a tiny amount of $\mathrm{Mg}$ by Na will not increase the $C_{p}$ at all due to the fact that $\mathrm{Na}$ is next to $\mathrm{Mg}$, and diffusivity $(D)$ of all samples $\mathrm{Mg}_{1-}$ ${ }_{x} \mathrm{Na}_{x} \mathrm{Ag}_{0.97} \mathrm{Sb}_{0.99}$ is shown in Figure 3(b). $C_{p}$ and $D$ are used to calculate the total thermal conductivity $(\kappa)$ of a series of doped samples using $\kappa=D \rho C_{p}$, where $\rho$ is the measured density of the samples. The densities of all the samples $\mathrm{Mg}_{1-x} \mathrm{Na}_{x} \mathrm{Ag}_{0.97} \mathrm{Sb}_{0.99}$ with $x=0,0.005,0.0075$, and 0.01 measured by Archimedes method are 6.17, 6.168, $6.165,6.185 \mathrm{~cm}^{-3}$, respectively, $\sim 98 \%$ of the theoretical density $6.31 \mathrm{~g} \mathrm{~cm}^{-3}$. The $C_{p}$ dependence of temperature shows that there are two phase transitions with increasing temperature, from $\alpha$ phase to $\beta$ phase at $\sim 33{ }^{\circ} \mathrm{C}$ and from $\beta$ phase to $\gamma$ phase at $\sim 360{ }^{\circ} \mathrm{C}$. The temperature dependence of the total thermal conductivity $(\kappa)$ of Na doped samples, along with the lattice contributions $\left(\kappa_{\mathrm{L}}\right)$, are plotted in Figure 3(c) and (d), respectively. The thermal conductivity decreases with temperature first, reaching a minimum $\kappa$ at around $75-100{ }^{\circ} \mathrm{C}$, and then increases from $100^{\circ} \mathrm{C}$ to $275^{\circ} \mathrm{C}$ due to the bipolar effect, which is consistent with electrical resistivity curves. As Na content increases, the thermal conductivity $\kappa$ increases and lattice thermal conductivity $\left(\kappa_{L}\right)$ decreases. The lattice thermal conductivity $\kappa_{L}$ was determined by subtracting the electronic contribution $\kappa_{\mathrm{e}}, \kappa_{L}=$ $\kappa-\kappa_{e}, \kappa_{e}$ is calculated using the Wiedemann-Franz relation $\kappa_{\mathrm{e}}=L \sigma T$, where $L$ is the Lorenz number, which can be obtained from fitting the respective Seebeck coefficient values with an estimate of the reduced chemical potential [36].

For the undoped sample $\mathrm{MgAg}_{0.97} \mathrm{Sb}_{0.99}$, the low thermal conductivity over the whole temperature range from 25 to $275^{\circ} \mathrm{C}$, shown in Figure 3(c), can be ascribed to the 
distorted structure, large unit cell and the strong phonon scattering due to the deficiencies at both the Ag and Sb sites, and small grain size. The Na doped samples with fairly good uniform grains in the range of $50-200 \mathrm{~nm}$ are very similar to the undoped $\mathrm{MgAg}_{0.97} \mathrm{Sb}_{0.99}$ sample.

SEM investigation was carried out on the freshly fractured surface of the bulk samples $\mathrm{Mg}_{0.9925} \mathrm{Na}_{0.0075} \mathrm{Ag}_{0.97} \mathrm{Sb}_{0.99}$ to examine the homogeneities of the grains and is shown in Figure 4(a). In order to further understand the grain structure, TEM images were taken and are shown in Figure 4(b) and (c). For samples $\mathrm{Mg}_{0.9925} \mathrm{Na}_{0.0075} \mathrm{Ag}_{0.97} \mathrm{Sb}_{0.99}$, the low magnification TEM image, Figure 4(b), shows the same results as SEM images, confirming the grains are in the range of 50-200nm. The black dots, which are circled in Figure 4(b), might be the nano precipitates. High resolution TEM image, shown in Figure 4(c), indicates the grains are crystallized.

The temperature dependent $Z T$ for $\mathrm{Mg}_{1-x} \mathrm{Na}_{x} \mathrm{Ag}_{0.97} \mathrm{Sb}_{0.99}(x=0,0.005,0.0075$, and 0.01 ) is presented in Figure 5. With increasing temperature, the $Z T$ value increases, reaching a peak $Z T \sim 1.26$ at about $250{ }^{\circ} \mathrm{C}$ for $\mathrm{Mg}_{0.9925} \mathrm{Na}_{0.0075} \mathrm{Ag}_{0.97} \mathrm{Sb}_{0.99}$. Na-doped samples show generally a little better performance. At $30^{\circ} \mathrm{C}$, we achieved $Z T$ of $\sim 0.8$ in samples $\mathrm{Mg}_{1-x} \mathrm{Na}_{x} \mathrm{Ag}_{0.97} \mathrm{Sb}_{0.99}$ with $x=0.005$ and 0.0075 .

Compatibility factor $c=(\sqrt{1+Z T}-1) / S T$, calculated from the temperature dependent Seebeck Coefficient and $Z T$, is regarded as a thermoelectric property essential for designing an efficient segmented thermoelectric device [37]. For a single material, it is called self-compatibility factor [38]. The physics of compatibility is about the matching of the physical properties over the whole length of the thermoelectric leg. The change in compatibility factor will have an effect on device performance since it is temperature dependent. A large difference of each individual property for the cold and hot side will cause incompatibility. Figure 6 shows the self-compatibility factors of all samples $\mathrm{Mg}_{1}$ ${ }_{x} \mathrm{Na}_{x} \mathrm{Ag}_{0.97} \mathrm{Sb}_{0.99}(x=0,0.005,0.0075$, and 0.01$)$. The self-compatibility factors of most $\mathrm{Na}$ doped samples vary less than $15 \%$. Compared to other materials, such as $\mathrm{Bi}_{0.4} \mathrm{Sb}_{1.6} \mathrm{Te}_{3}$, the self-compatibility of MgAgSb-based materials shows much less temperature dependent, which will contribute to a relatively higher efficiency.

To predict the thermoelectric performance under a certain temperature difference, a numerically iterative calculation was carried out based on a finite difference model [39, 40] in which the temperature dependence of thermoelectric properties was taken into account. The governing equation of 1-D energy balance in a differential element of thermoelectric leg is, 


$$
\frac{d}{d x}\left(\kappa(T(x)) \frac{d T(x)}{d x}\right)+J^{2} \rho(T(x))-J T(x) \frac{d S(T(x))}{d x}=0
$$

where, $T(x)$ is temperature distribution through a thermoelectric leg as a function of position $x\left(x=0\right.$ for $\left.T_{H}\right)$, and $\mathrm{J}$ is electric current density, $\kappa(T(x)), \rho(T(x))$ and $S(T(x))$ are temperature dependent thermal conductivity, electric resistivity, and Seebeck coefficient, repectively. The left hand side three terms represent conduction heat, Joule heat, and Thomson heat, respectively. By applying Eq. (1) into each differential element, numerically converged temperature profile and current density followed by output power and conversion efficiency can be obtained. In this model, an adiabatic condition is assumed and only thermoelectric leg is considered by ignoring electrical contact resistances. Two sets of the leg dimensions are examined: $1.0 \mathrm{~mm}$ and $1.5 \mathrm{~mm}$ of leg lengths with a fixed cross section of $1.5 \mathrm{~mm}$ x $1.5 \mathrm{~mm}$. Figure 7(a) shows the generated output power density, $\mathrm{W} \mathrm{cm}^{-2}$, at various temperature differences. As compared with the undoped $\mathrm{MgAg}{ }_{0.97} \mathrm{Sb}_{0.99}$, the output power of $\mathrm{Na}$-doped $\mathrm{Mg}_{0.9925} \mathrm{Na}_{0.0075} \mathrm{Ag}_{0.97} \mathrm{Sb}_{0.99}$ increases by $8.1 \%$ at $\Delta T=275^{\circ} \mathrm{C}$ in both $L=1.0$ and $1.5 \mathrm{~mm}$ mainly due to the enhancement of the power factor by lowering electric resistivity while the conversion efficiency is only improved by 3.0\%. The reason why the improvement of the leg efficiency is smaller than that of the output power because the improved output power is offset by the larger required input heat flux as shown in Figure 7(b) to maintain the constant temperature difference, which is caused by the increased thermal conductivity as shown in Figure 3(b). The leg with $L=1.0 \mathrm{~mm}$ gives a larger power output by $50 \%$ at $\Delta$ $T=275^{\circ} \mathrm{C}$ as compared to the leg with $L=1.5 \mathrm{~mm}$ since the shorter leg reduces the electrical resistance resulting in more electric current flow under the constant load voltage based on the fixed $\Delta T s$. Thus, a shorter thermoelectric leg is desired to boost up the output power generation once the boundary temperature $T_{H}$ and $T_{C}$ are constantly maintained, which can improve volumetric power density $\left(\mathrm{W} \mathrm{m}^{-3}\right)$, mass power density $\left(\mathrm{W} \mathrm{kg}^{-1}\right)$, and cost-effectiveness ( $\mathrm{W}^{-1}$ ) as well. However, one also needs to consider that a shorter leg requires more heat flux to generate the same temperature gradient through the reduced length, where the conversion efficiency in this ideal model has no benefit as shown in Figure 7(b). In addition, electric contact resistance, thermal resistance of electrodes and insulation materials, and thermal shear stress at bonding interfaces of dissimilar materials are also taken into account to figure out proper geometry of a leg.

\section{Conclusion}

In conclusion, $\mathrm{Na}$ alloying to $\mathrm{Mg}$ of the samples $\mathrm{Mg}_{1-x} \mathrm{Na}_{x} \mathrm{Ag}_{0.97} \mathrm{Sb}_{0.99}(x=0.005,0.0075$, 0.01) enhances the power factor by increasing carrier concentration. Higher power factor results in higher output power but not too much higher $Z T$ s due to higher thermal conductivity caused by the higher electrical conductivity. Further optimization of alloying in each site and carrier concentration could lead to even higher power factor, higher $Z T$, and ultimately higher output power. 


\section{Acknowledgment}

The work performed at University of Houston is funded by US Air Force Office of Scientific Research's MURI program under contract FA9550-10-1-0533 (synthesis of $\left.\mathrm{Mg}_{1-\mathrm{x}} \mathrm{Na}_{\mathrm{x}} \mathrm{Ag}_{0.97} \mathrm{Sb}_{0.99}\right)$ and DOE under contract number DE-FG02-13ER46917 / DESC0010831 (characterization). 


\section{References}

1. S. B. Riffat, X. Ma, Applied Thermal Engineering 23 (2003) 913.

2. R. Chein, G. Huang, Applied Thermal Engineering 24 (2004) 2207.

3. X. Gou, H. Xiao, S. Yang, Applied Energy 87 (2010) 3131.

4. D. Kraemer, B. Poudel, H. P. Feng, J. C. Caylor, B. Yu, X. Yan, Y. Ma, X. Wang, D. Wang, A. Muto, K. McEnaney, M. Chiesa, Z. F. Ren, G. Chen, Nature Materials 10 (2011) 532.

5. M. Zebarjadi, K. Esfarjani, M. S. Dresselhaus, Z. F. Ren, G. Chen, Energy and Environmental Science 5 (2012) 5147.

6. B. Poudel, Q. Hao, Y. Ma, Y.C. Lan, A. Minnich, B. Yu, X. Yan, D.Z. Wang, A. Muto, D. Vashaee, X. Chen, J. Liu, D.S. Dresselhaus, G. Chen, Z.F. Ren, Science 320 (2008) 634.

7. W. Liu, X. Yan, G. Chen, Z. F. Ren, Nano Energy 1 (2012) 42.

8. B. C. Sales, D. Mandrus, B. C. Chakoumakos, V. Keppens, and J. R. Thompson, Physical Review B 56 (1997) 15081.

9. H. Kleinke, Chemistry of Materials 22 (2010) 604.

10. S. Ishiwata, Y. Shiomi, J. S. Lee, M. S. Bahramy, T. Suzuki, M. Uchida, R. Arita, Y. Taguchi, Y. Tokura, Natural Materials 12 (2013) 512.

11. M. S. Dresselhaus, G. Chen, M. Y. Tang, R. G. Yang, H. Lee, D. Z. Wang, Z. F. Ren, J. P. Fleurial, P. Gogna, Advanced Materials 19 (2007) 1043.

12. S. Faleev, F. Léonard, Physical Review B 77 (2008) 214304.

13. J. Martin, L. Wang, L. Chen, G. Nolas, Physical Review B 79 (2009) 115311.

14. Q. Zhang, Q. Zhang, S. Chen, W. Liu, K. Lukas, X. Yan, H. Wang, D. Wang, C. Opeil, G. Chen, Z. F. Ren, Nano Energy 1 (2012) 183.

15. Y. Pei, A. LaLonde, S. Iwanaga, G. J. Snyder, Energy and Environmental Science 4 (2011) 2085.

16. Y. Pei, X. Shi, A. LaLonde, H. Wang, L. Chen, G. J. Snyder, Nature 473 (2011) 66.

17. Q. Zhang, F. Cao, K. Lukas, W. Liu, K. Esfarjani, C. Opeil, D. Broido, D. Parker, D. J. Singh, G. Chen, Z. F. Ren, Journal of American Chemistry Society 134 (2012) 17731. 
18. Q. Zhang, S. Yang, Q. Zhang, S. Chen, W. Liu, H. Wang, Z. Tian, D. Broido, G. Chen, Z. F. Ren, Nanotechnology 24 (2013) 345705.

19. M. M. Koza, M. R. Johnson, R. Viennois, H. Mutka, L. Girard, D. Ravot, Nature Materials 7 (2008) 805.

20. X. Shi, J. Yang, J. R. Salvador, M. Chi, J. Y. Cho, H. Wang, S. Bai, J. Yang, W. Zhang, L. Chen, Journal of American Chemistry Society 133 (2011) 7837.

21. Q. Jie, H. Wang, W. Liu, H. Wang, G. Chen, Z. F. Ren, Physical Chemistry Chemical Physics 15 (2013) 6809.

22. J. Androulakis, P. Migiakis, J. Giapintzakis, Applied Physics Letters 84 (2004) 1099.

23. S. Walia, S. Balendhran, H. Nili, S. Zhuiykov, G. Rosengarten, Q.H. Wang, M. Bhaskaran, S. Sriram, M.S. Strano, K. Kalantar-zadeh, Progress in Materials Science 58 (2013) 1443.

24. X. Yan, G. Joshi, W. Liu, Y. Lan, H. Wang, S. Lee, J. W. Simonson, S. J. Poon, T. M. Tritt, G. Chen, Z. F. Ren, Nano Letters 11 (2011) 556.

25. X. Yan, W. Liu, H. Wang, S. Chen, J. Shiomi, K. Esfarjani, H. Wang, D. Wang, G. Chen, Z. F. Ren, Energy and Environmental Science 5 (2012) 7543.

26. G. Joshi, T. Dahal, S. Chen, H. Wang, J. Shiomi, G. Chen, Z. F. Ren, Nano Energy 2 (2013) 82.

27. X. Yan, W. Liu, S. Chen, H. Wang, Q. Zhang, G. Chen, Z. F. Ren, Advanced Energy Materials 3 (2013) 1195.

28. S. Chen, Z. F. Ren, Materials Today 16 (2013) 387.

29. S. Chen, K. C. Lukas, W. Liu, C. P. Opeil, G. Chen, Z. F. Ren, Advanced Energy Materials 3 (2013) 1210.

30. S. K. Mishra, Journal of Physics: Condensed Matter 9 (1996) 461.

31. X. B. Zhao, X. H. Ji, Y. H. Zhang, T. J. Zhu, J. P. Tu, X. B. Zhang, Applied Physics Letters 86 (2005) 062111.

32. M. J. Kirkham, A. M. dos Santos, C. J. Rawn, E. Lara-Curzio, J. W. Sharp, A. J. Thompson, Physical Review B 85 (2012) 144120.

33. H. Zhao, J. Sui, Z. Tang, Y. Lan, Q. Jie, D. Kraemer, K. McEnaney, A. Guloy, G. Chen, Z. F. Ren, Nano Energy 7 (2014) 97. 
34. M. Lee, L. Viciu, L. Li, Y. Wang, M. L. Foo, S. Watauchi, R. A. Pascal, Jr., R. J. Cava, N. P. Ong, Nature Materials 5 (2006) 537.

35. J. He, L. D. Zhao, J. C. Zheng, J. W. Doak, H. Wu, H. Q. Wang, Y. Lee, C. Wolverton, M. G. Kanatzidis, V. P. Dravid, Journal of American Chemistry Society 135 (2013) 4624.

36. D. M. Rowe, C. M. Bhandari, Moden thermoelectric, Reston Publishing Company, Inc., Virginia , (1983) .

37. G. Snyder, T. Ursell, Physical Review Letters 91 (2003) 148301.

38. W. Seifert, G.J. Snyder, E.S. Toberer, C. Goupil, K. Zabrocki, E. Müller, Physica Status Solidi (a) 210 (2013) 1407.

39. G. D. Mahan, Journal of Applied Physics 70 (1991) 4551.

40. T. P. Hogan, T. Shih, Modeling and Characterization of Power Generation Modules Based on Bulk Materials. CRC Press, Boca Raton (FL), (2006). 


\section{Figure Captions}

Figure 1. XRD patterns of $\mathrm{Mg}_{1-x} \mathrm{Na}_{x} \mathrm{Ag}_{0.97} \mathrm{Sb}_{0.99}(x=0,0.005,0.0075$, and 0.01)

Figure 2. Temperature dependent thermoelectric properties of $\mathrm{Mg}_{1-x} \mathrm{Na}_{x} \mathrm{Ag}_{0.97} \mathrm{Sb}_{0.99}(x=0$, 0.005, 0.0075, and 0.01): (a) Electrical resistivity; (b) Seebeck coefficient; and (c) power factor.

Figure 3. Temperature dependent thermal transport properties of $\mathrm{Mg}_{1-x} \mathrm{Na}_{x} \mathrm{Ag}_{0.97} \mathrm{Sb}_{0.99}(x$ $=0,0.005,0.0075$, and 0.01): (a) Specific heat; (b) thermal diffusivity; (c) total thermal conductivity; and (d) lattice thermal conductivity.

Figure 4. SEM and TEM images of sample $\mathrm{Mg}_{0.9925} \mathrm{Na}_{0.0075} \mathrm{Ag}_{0.97} \mathrm{Sb}_{0.99}$ : (a) SEM image; (b) medium magnification TEM image with selected area electron diffraction pattern as the inset; and (c) high resolution TEM image.

Figure 5. Temperature dependent $Z T$ for $\mathrm{Mg}_{1-x} \mathrm{Na}_{x} \mathrm{Ag}_{0.97} \mathrm{Sb}_{0.99}(x=0,0.005,0.0075$, and $0.01)$

Figure 6. Thermoelectric self-compatibility factors of $\mathrm{Mg}_{1-x} \mathrm{Na}_{x} \mathrm{Ag}_{0.97} \mathrm{Sb}_{0.99}(x=0,0.005$, 0.0075, and 0.01). The self-compatibility factor of $\mathrm{Bi}_{0.4} \mathrm{Sb}_{1.6} \mathrm{Te}_{3}$ is also plotted for comparison.

Figure 7. Output power of different dimensions. (a) Output power generation the maximum power generation mode of $\mathrm{R}_{\mathrm{L}} / \mathrm{R}_{\text {leg }} \sim 1\left(\mathrm{R}_{\mathrm{L}}\right.$ : load resistance and $\mathrm{R}_{\text {leg }}$ : leg resistance) according to the temperature difference and leg length at the fixed cross section area, $\mathrm{a}=1.5 \mathrm{~mm}$, and (b) output power density according to its input heat flux at the maximum efficiency mode of $\mathrm{R}_{\mathrm{L}} / \mathrm{R}_{\mathrm{leg}} \sim 1.4$ at $\Delta \mathrm{T}=275^{\circ} \mathrm{C}$. 
Table 1. Carrier concentration and Hall mobility at room temperature of $\mathrm{Mg}_{1-}$ ${ }_{x} \mathrm{Na}_{x} \mathrm{Ag}_{0.97} \mathrm{Sb}_{0.99}(x=0,0.005,0.0075$, and 0.01).

\begin{tabular}{c|cccc}
\hline $\mathrm{Mg}_{1-x} \mathrm{Na}_{x} \mathrm{Ag}_{0.97} \mathrm{Sb}_{0.99}$ & $x=0$ & $x=0.005$ & $x=0.0075$ & $x=0.01$ \\
\hline $\begin{array}{c}\text { Carrier concentration } \\
\left(10^{19} \mathrm{~cm}^{-3}\right)\end{array}$ & 2.413 & 3.198 & 3.49 & 3.455 \\
$\begin{array}{c}\text { Hall mobility } \\
\left(\mathrm{cm}^{2} \mathrm{~V}^{-1} \mathrm{~s}^{-1}\right)\end{array}$ & 70.2 & 70.3 & 74.9 & 70.1 \\
\hline
\end{tabular}




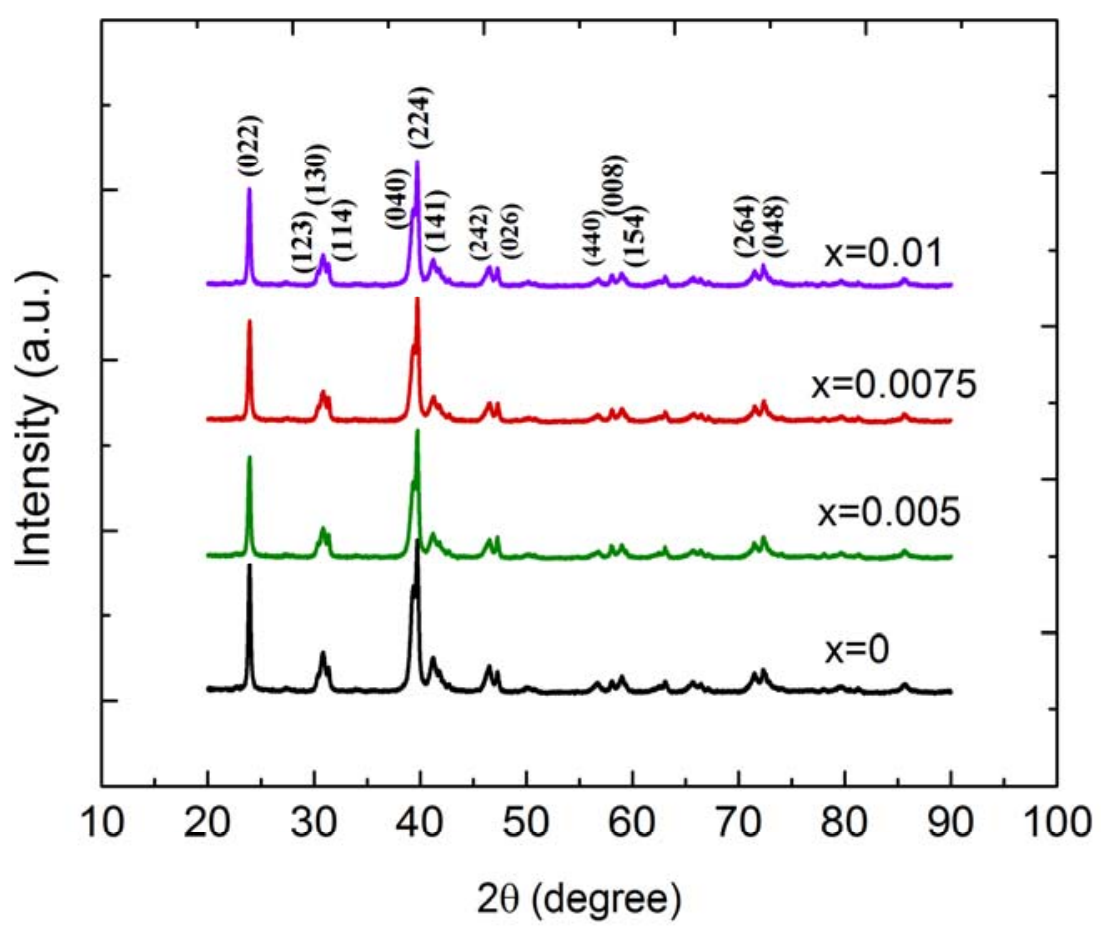

Figure 1 Jing Shuai et al. 

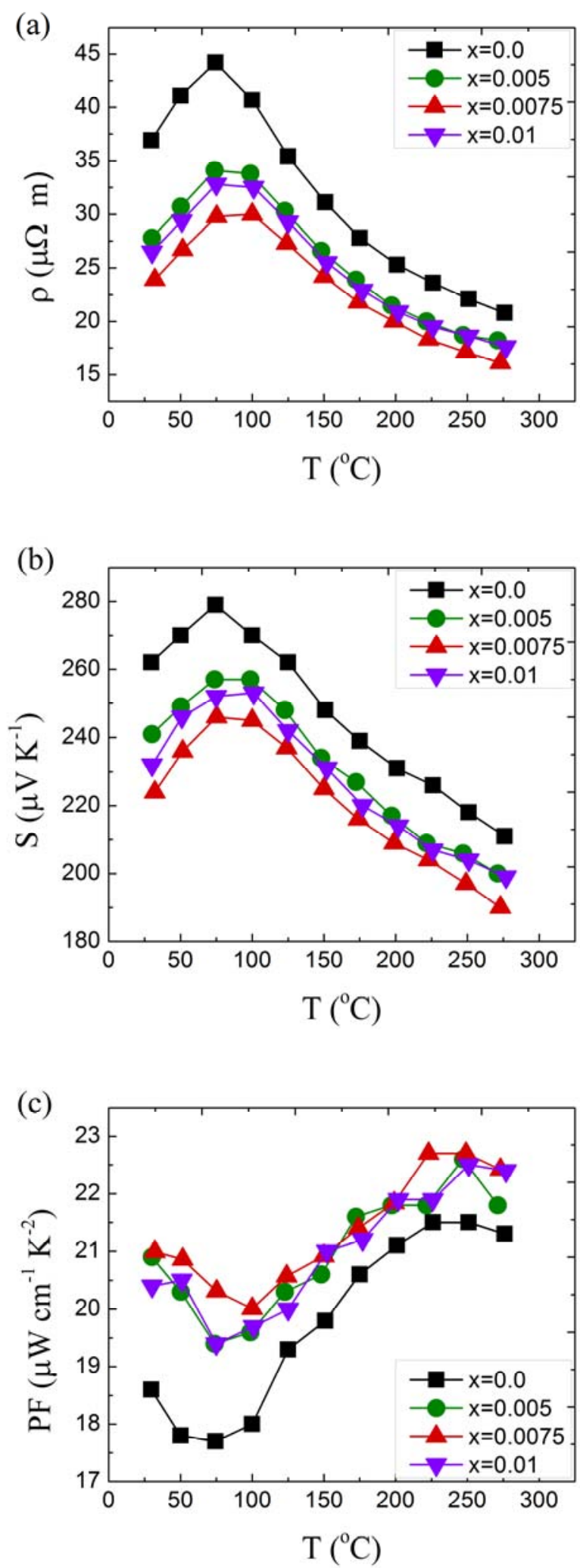

Figure 2 Jing Shuai et al. 

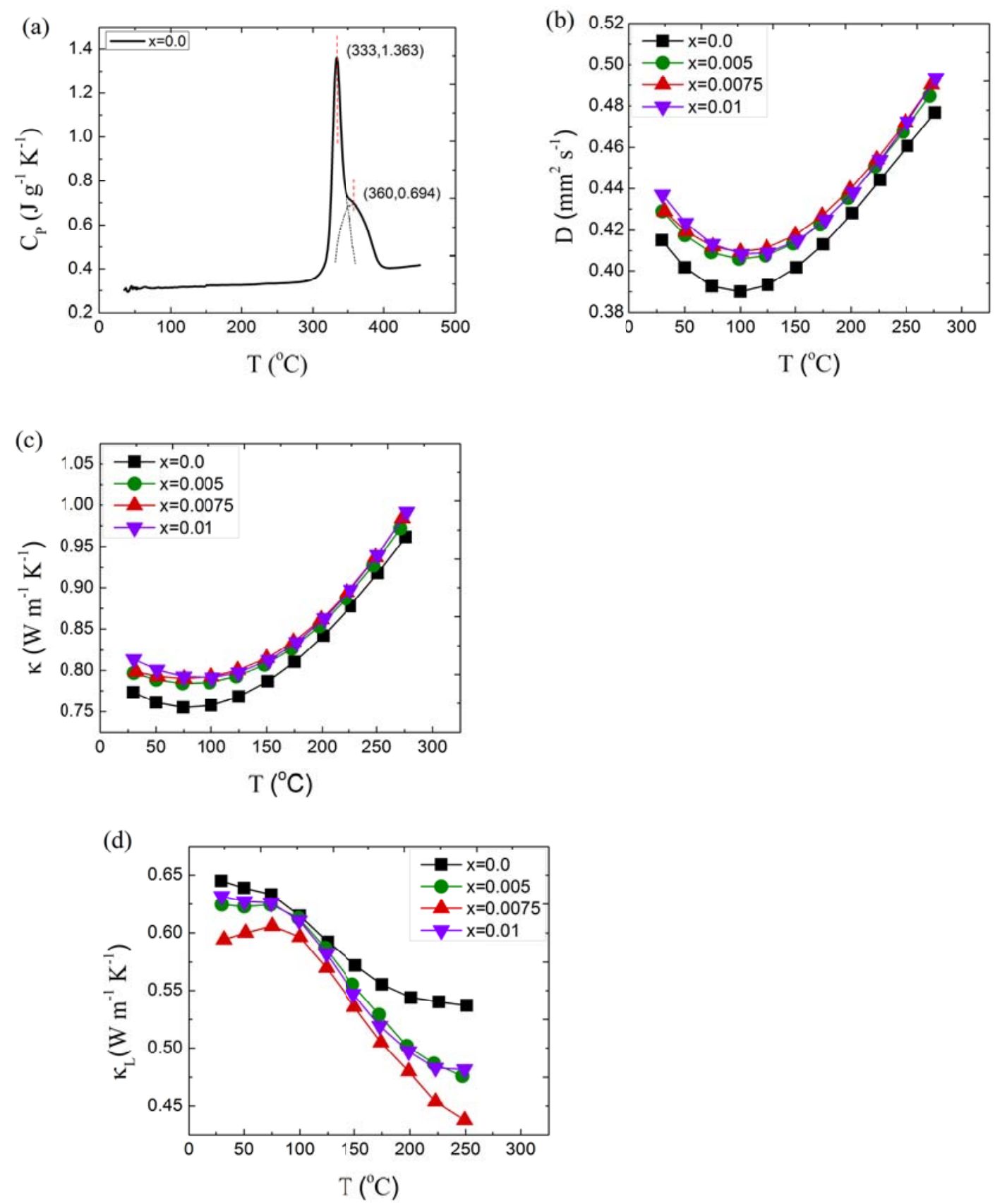

Figure 3 Jing Shuai et al. 

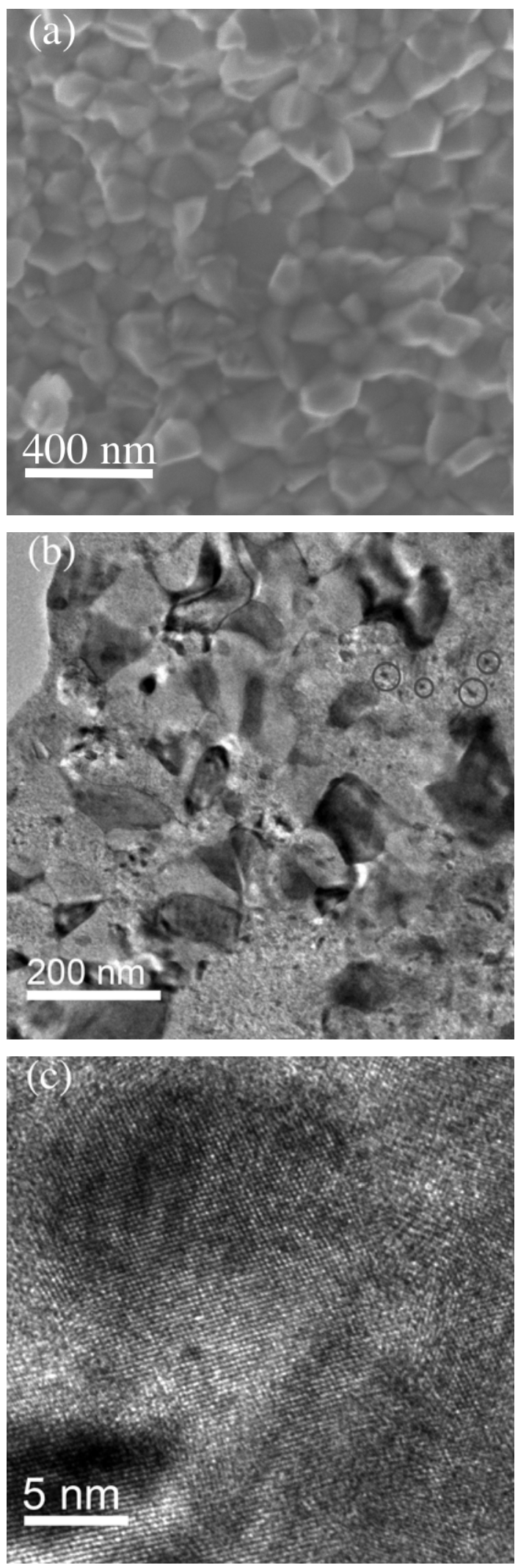

Figure 4 Jing Shuai et al. 


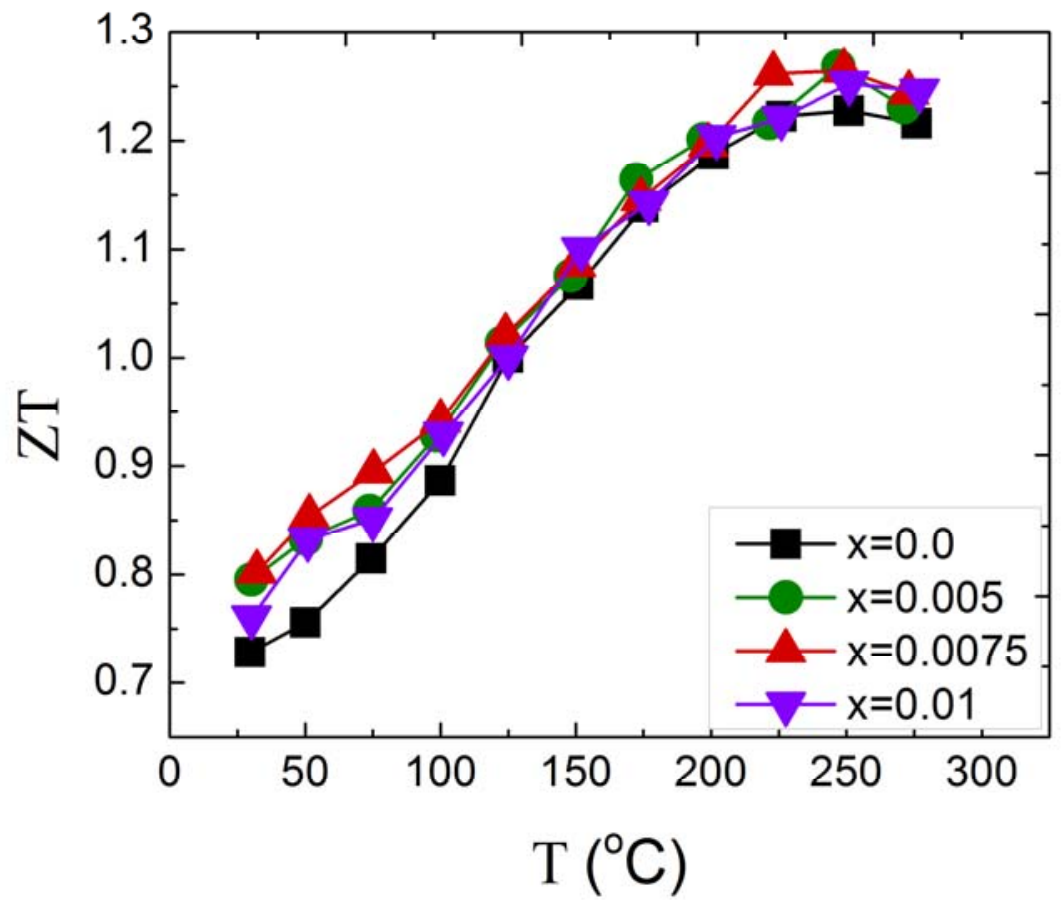

Figure 5 Jing Shuai et al. 


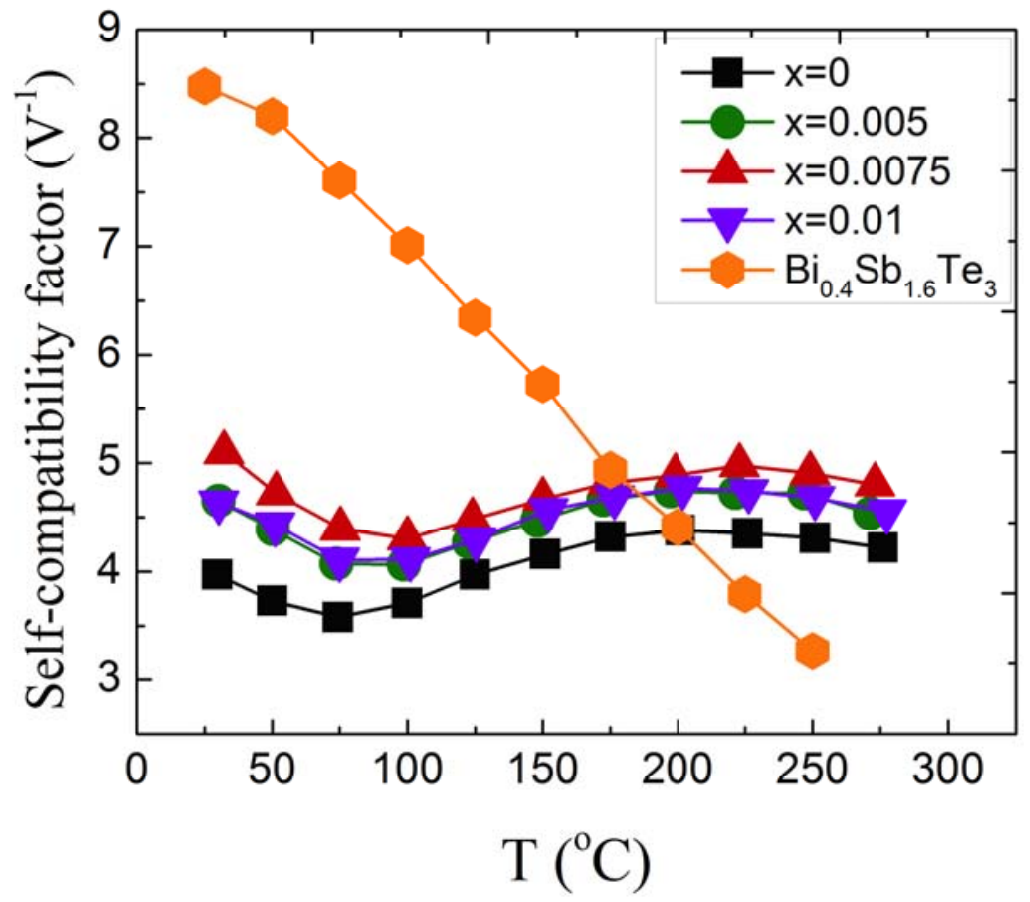

Figure 6 Jing Shuai et al. 

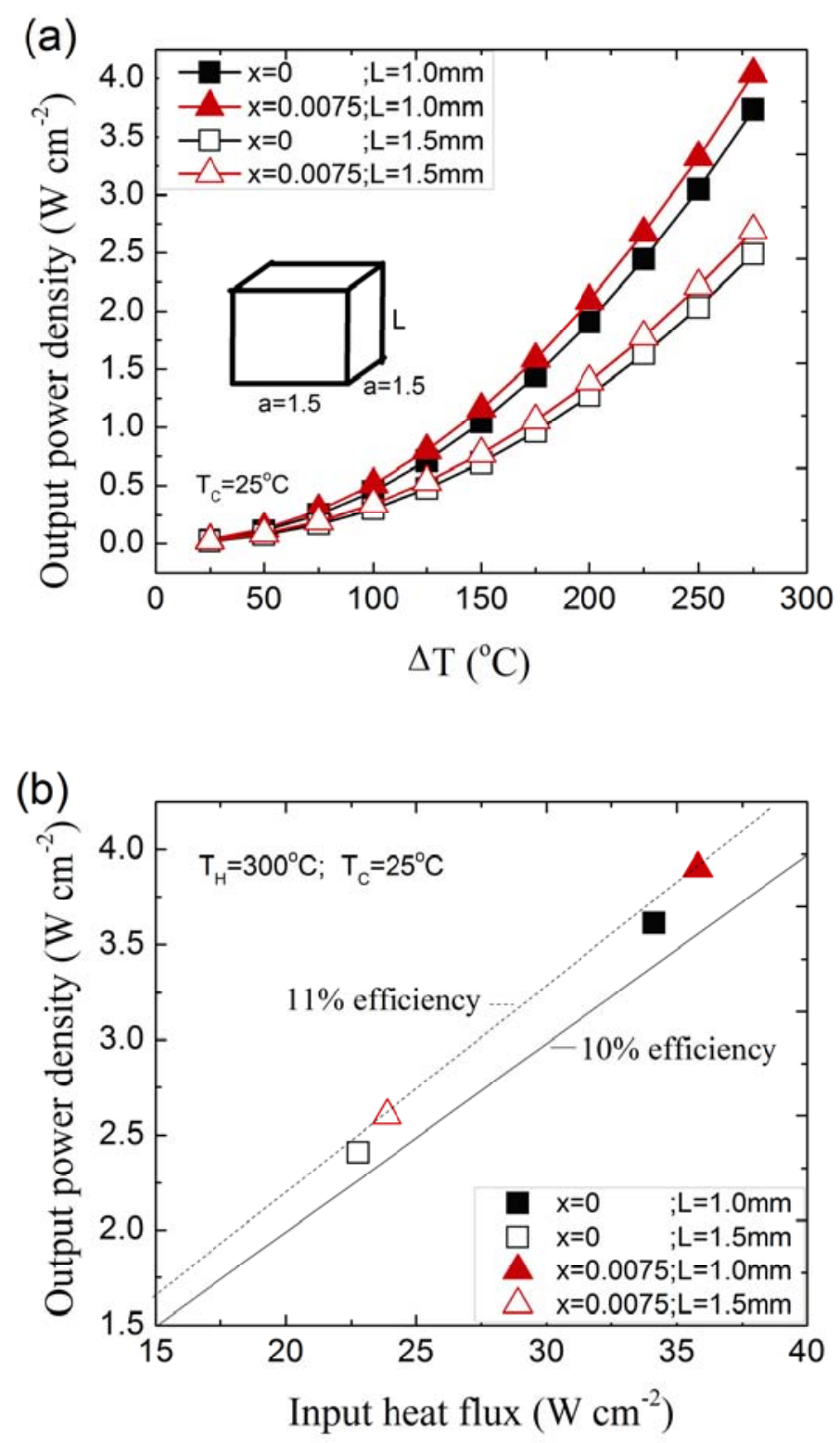

Figure 7 Jing Shuai et al. 


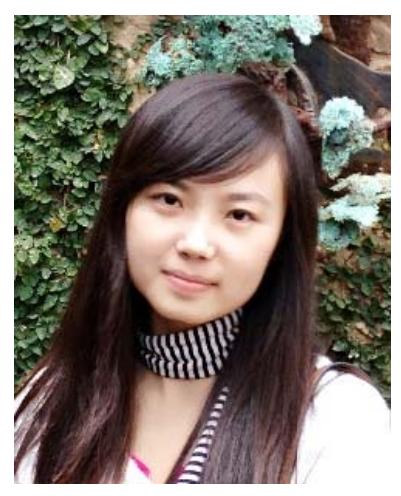

Jing Shuai is currently a Ph.D. candidate in the Department of Physics at the University of Houston, USA. She received her Bachelor's degree from Material Science and Engineering at Nanjing University in China. Her current research is mainly on nanostructured thermoelectric materials.

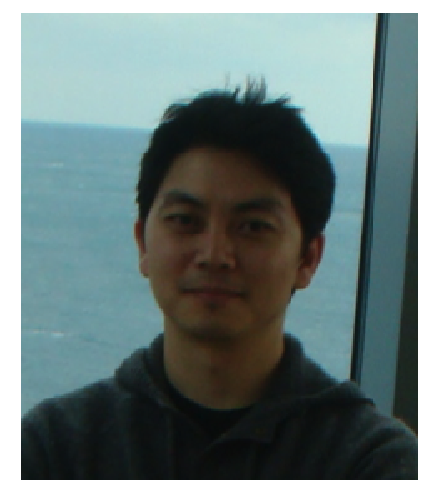

Dr. Hee Seok Kim is currently a postdoctoral fellow in the Department of Physics and TcSUH at the University of Houston, TX, USA. He received his Ph.D. degree in Mechanical Engineering from University of Washington, WA, USA in 2013, Master and Bachelor degrees from Mechanical Engineering at Sungkyunkwan University in Korea. His current research focuses on a design of thermoelectric devices and power/efficiency measurement systems from material to device level. 


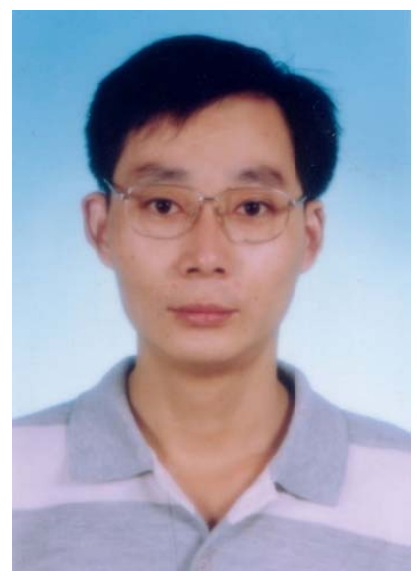

Dr. Yucheng Lan is currently an Associate Professor in the Department of Physics at Morgan State University. He obtained his Ph.D. degree from the Institute of Physics, Chinese Academy of Sciences, master and bachelor degrees from Jilin University, China. He specializes in X-ray powder diffraction, transmission electron microscopy, scanning electron microscopy and Raman scattering. He has published extensively in the area of superconductors, III-V nitrides, thermoelectric materials, photocatalytic materials, and nanosensors.

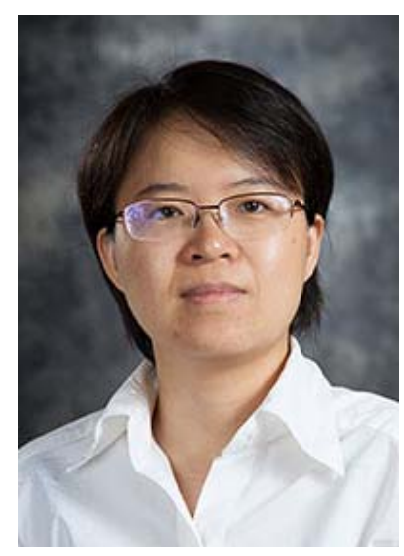

Dr. Shuo Chen is currently an Assistant Professor in the Department of Physics at University of Houston. She earned her B.S. degree in Physics at Peking University, China, and a Ph.D. degree from the Department of Physics at Boston College. Her research interests include the synthesis, in situ and ex situ characterization, and application of nanomaterials for thermal and electrochemical energy conversion and storage. 


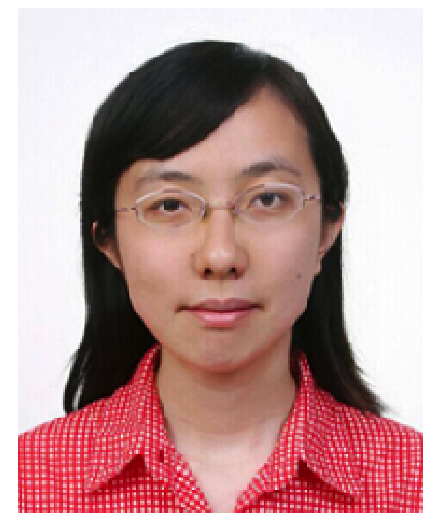

Yuan Liu is currently a graduate student pursuing her $\mathrm{PhD}$ degree in the Department of Physics at the University of Houston, USA. She obtained her B.S. Degree in Physics from Nanjing University, China. Her current research is mainly on thermoelectrics, nano materials and nano fabrication.

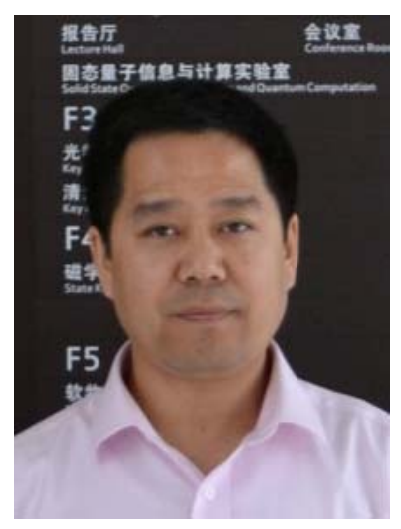

Dr. Huaizhou Zhao is currently an Associate Professor in the Institute of Physics at Chinese Academy of Sciences. He obtained his Ph.D. degree in Condensed Matter Physics from the Institute of Physics, Chinese Academy of Sciences in 2006, and Master degree in Solid State Chemistry from Beijing Normal University in 2003. He specializes in X-ray powder diffraction structural refinement, Solid State Chemistry, Nanotechnology. He has published extensively in the area of metal nitrides, nanosensors, and thermoelectric materials. 


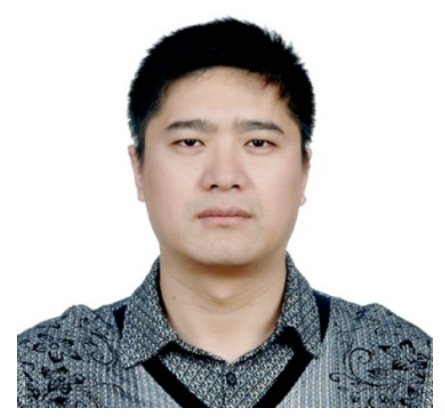

Dr. Jiehe Sui is currently a visiting scholar in the Department of Physics and TcSUH at the University of Houston, USA. He received his Ph.D. degree in Materials Science and Engineering from Harbin Institute of Technology, China. His current research is mainly on synthesis and characterization of nanostructured thermoelectric materials.

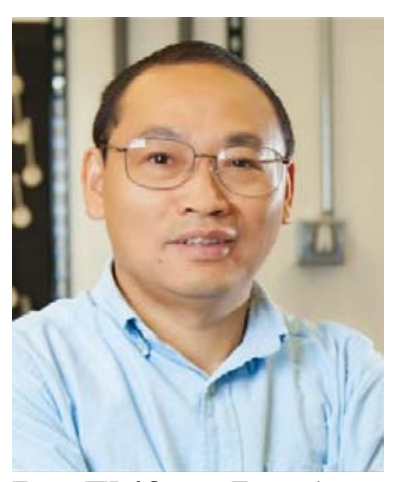

Dr. Zhifeng Ren is currently an M.D. Anderson Chair Professor in the Department of Physics and TcSUH at the University of Houston. He obtained his Ph.D. degree from the Institute of Physics Chinese Academy of Sciences in 1990, master degree from Huazhong University of Science and Technology in 1987, and bachelor degree from Sichuan Institute of Technology in 1984. He was a postdoc and research faculty at SUNY Buffalo (1990-1999) before joining BC as an Associate Professor in 1999. He specializes in thermoelectric materials, solar thermoelectric devices \& systems, photovoltaic materials \& systems, carbon nanotubes \& semiconducting nanostructures, nanocomposites, bio agent delivery \& bio sensors, flexible transparent conductors, superconductors, etc. He is a fellow of the APS and AAAS. Recently he was elected as a fellow of the National Academy of Inventors (NAI). He was recipient of the R\&D 100 award in 2008 and the 2014 Edith \& Peter O’Donnell Award in Science of The Academy of Medicine, Engineering, and Science of Texas. 

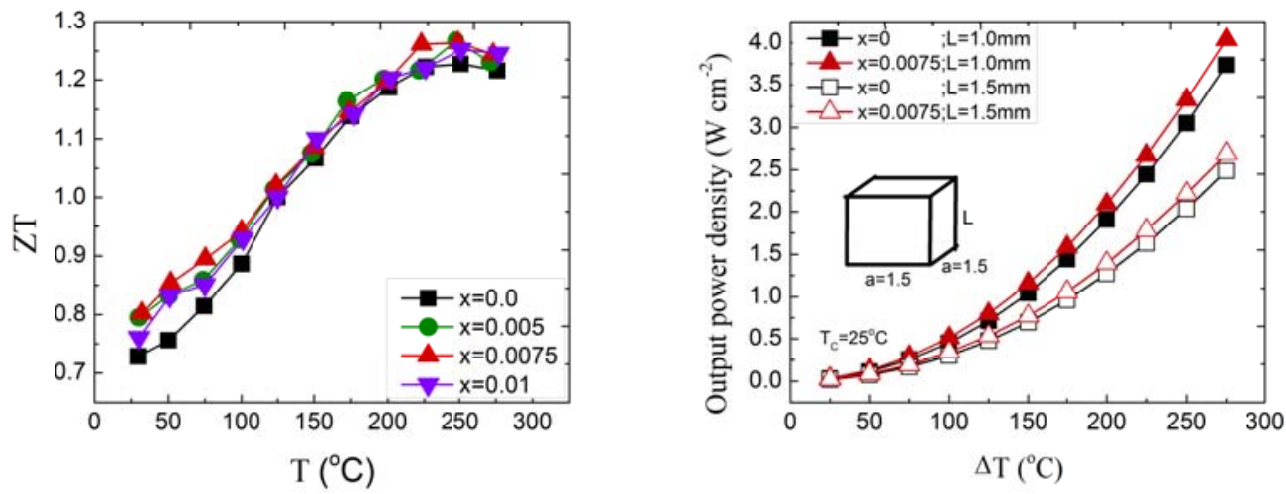

Na doping in $\mathrm{Mg}$ site of the samples $\mathrm{Mg}_{1-\mathrm{x}} \mathrm{Na}_{\mathrm{x}} \mathrm{Ag}_{0.97} \mathrm{Sb}_{0.99}$ effectively enhances the power factor by increasing carrier concentration. The ZT value was improved from 1.2 at 250 for $\mathrm{MgAg}_{0.97} \mathrm{Sb}_{0.99}$ sample to 1.26 at 250 for $\mathrm{Mg}_{0.925} \mathrm{Na}_{0.075} \mathrm{Ag}_{0.97} \mathrm{Sb}_{0.99}$ sample. High power factor results in higher output power, which is good for fabricating thermoelectric devices. 